Original Research Article

\title{
Drug utilisation pattern in geriatric patients of a teritiary care teaching hospital: a retrospective study
}

\author{
Naveen Kumar Tamma, Prasanth Kumar Patnaik*, Srinivasu Karedla
}

Department of Pharmacology, Mahavir Institute of Medical Sciences, Vikarabad, Hyderabad, Telangana, India

Received: 29 August 2019

Revised: 10 October 2019

Accepted: 12 October 2019

*Correspondence to:

Dr. Prasanth Kumar Patnaik, Email: prasanthpaul86 @gmail.com

Copyright: (C) the author(s), publisher and licensee Medip Academy. This is an openaccess article distributed under the terms of the Creative Commons Attribution NonCommercial License, which permits unrestricted noncommercial use, distribution, and reproduction in any medium, provided the original work is properly cited.

\begin{abstract}
Background: The objective of the study was to assess the prescribing pattern of drugs in geriatrics patient in a tertiary care hospital.

Methods: A retrospective observational study was conducted by department of Pharmacology for a period of one year in patients above 65 years from case sheets of medical record section. WHO basic indicators were used for studying the prescribing pattern of drugs.

Results: A total of 200 patients were included in the study. Respiratory tract and gastrointestinal infections were most commonly found among patients of geriatric age group. Among antibiotics ceftriaxone, cefixime, ampicillin, amoxicillin, azithromycin, ciprofloxacin, cotrimaxazole for upper respiratory tract infections and rantidine, norfloxacin for gastrointestinal tract infections were maximum utilized. Polypharmacy was prevalent and majority of drugs prescribed were by brand names because of free supply of drugs.

Conclusions: There is a need to bring changes in the prescribing practices with particular emphasis on generic drug and restricting polypharmacy. Also antibiotic policy needs to be introduced in the hospital and continuous medical education besides evidence based medicine approach for rationale use of drugs.
\end{abstract}

Keywords: Drug utilization, Geriatrics patients, Retrospective, Polypharmacy

\section{INTRODUCTION}

In the recent years studies on drug utilization have become a potential tool to be used in the evaluation of health systems.

Drug utilization is defined as "the prescribing, dispensing, administering, and ingesting of drugs". Drug utilization studies can also be used as a quality assurance tool to examine the prescribing characteristics of different medical practitioners.
The World Health Organization has estimated that half of all medicines used worldwide are prescribed or dispensed inappropriately. With consequences including increased patient morbidity, mortality, healthcare expenditures and wastage of resources, the irrational use of medicines is recognized as a major global problem.

Prescribing to older patients is unique challenge because premarketing drug trials often exclude geriatric patients and approved doses may not be appropriate for older adults. ${ }^{1}$ 
Drug utilisation studies can provide highly valuable information, at reasonable price, on the cost and effects (harmful and beneficial) of drugs. Such studies make available much useful information including indirect data on morbidity, therapeutic compliance and the incidence of adverse reactions.

Conducting periodic studies of pattern of drug use in various hospital settings or patient populations is therefore essential to critically analyse the current hospital drug policies and to make recommendations based on various guidelines to improve upon the current drug usage pattern in the future, if needed.

A retrospective drug utilization study is an approved, systematic process that captures, reviews, analyses and interprets aggregate medication use data within specific health care environments. ${ }^{2}$

According to the results of a longitudinal study by Veehof et al, polypharmacy is increasing. ${ }^{3}$ Pharmacist as the most accessible health professionals have significant role on informing of the patients about rational drug use. $^{4,5}$

Inappropriate use of drug also leads to increased cost of medical care, antimicrobial resistance, adverse effects and patient mortality. Hence the drug utilization evaluation studies becomes one of the potential tools in evaluation of health system. ${ }^{6,7}$

The objective of this study was to decrease the medication error and their related problems, to observe the prescribing pattern used in upper respiratory tract infection, gastrointestinal infections and to assess the rationality of prescribing to current recommended guidelines.

\section{METHODS}

This drug utilization study was a cross sectional retrospective study conducted at the Mahavir Institute of Medical Sciences, Vikarabad, Telangana over period of one year from April 2018 to May 2019. Institutional ethics committee permission was taken before conduct of study.

A total of 200 patients age group of 65 years and above were included in the study. Exclusion criteria are pregnant women and those who denied participation.

Data was collected by evaluating case sheets of in patients stored at the medical records of the hospital. Data collection was done using a predesigned proforma which included patient characteristics such as age, gender, occupation, diagnosis, patient medical history and prescription characteristics such as name of the drug, strength, dosage forms and number of drugs dispensed. National List of Essential Medicines 2018-19 of India was used for assessing the number of drugs prescribed from the essential list.

\section{Statistical analysis}

Recorded data were analysed by Microsoft Office Excel.

\section{RESULTS}

Out of 200 patients analysed, 120 (60\%) were age group of 65 to $70,80(40 \%)$ patients between age of 70 to 75 years. The distribution of patients was similar for males and females. The patients included were based on clinical diagnosis most common being respiratory infections include pharyngitis, laryngitis, chronic obstructive pulmonary diseases and gastrointestinal diseases. The other clinical conditions include urinary tract infections, gastrointestinal tract infections, skin and soft tissue infections, anaemia and pelvic inflammatory disease with less number of prescriptions (Table 2).

Table 1: Demographic distribution of the patients.

\begin{tabular}{|lll|}
\hline Age group (in years) & No. of patients & $\%$ \\
\hline $\mathbf{6 5 - 7 0}$ & 120 & 60 \\
\hline $\mathbf{7 1 - 7 5}$ & 80 & 40 \\
\hline
\end{tabular}

Table 2: Common diagnosis among patients.

\begin{tabular}{|lll|}
\hline Diagnosis & $\begin{array}{l}\text { No. of } \\
\text { cases }\end{array}$ & $\%$ \\
\hline Upper respiratory tract infections & 60 & 30 \\
\hline Gastrointestinal infections & 35 & 17.5 \\
\hline Skin and soft tissue infections & 20 & 10 \\
\hline Pelvic inflammatory diseases & 15 & 7.5 \\
\hline Urinary tract infections & 25 & 12.5 \\
\hline Anemia & 45 & 22.5 \\
\hline
\end{tabular}

Table 3: Number of prescriptions for various class of drugs.

\begin{tabular}{|ll|l|}
\hline Antibiotics prescribed & No. of patients & $\%$ \\
\hline Cephalosporins & 70 & 35 \\
\hline Macrolides & 20 & 10 \\
\hline Pencillins & 50 & 25 \\
\hline Fluoroquinolones & 40 & 20 \\
\hline Tetracyclines & 14 & 7 \\
\hline Antitubercular drugs & 5 & 2.5 \\
\hline Rantidine & 98 & 49 \\
\hline Anemia & 8 & 4 \\
\hline Diclofenac & 90 & 45 \\
\hline Others & 5 & 2.5 \\
\hline
\end{tabular}

Anti-infective agents followed by drugs acting on gastrointestinal system were the most common class of drugs prescribed. Nutritional supplements, antiinflammatory agents and iron tablets were the other class of drugs used (Table 3). Oral route was the most common 
route of drug administration followed by injectables for emergency conditions.
Irrational drug combinations were observed in few patients (Table 4).

Table 4: Irrational drug combinations.

\begin{tabular}{|ll|}
\hline Drug combinations & $\begin{array}{l}\text { Though claimed to be broad spectrum, combining (antiamoebic) with fluoroquinolone } \\
\text { (antibacterial) is irrational because patient suffers only from one type of diarrhoea. Using } \\
\text { this combination adds to cost, adverse effects and may encourage resistance. }\end{array}$ \\
\hline Amoxycillin+cloxacillin & $\begin{array}{l}\text { Amoxycillin is inactive against staphylococcus, as most strains produce } \beta \text {-lactamase and } \\
\text { cloxacillin is not so active against streptococci. For any given infection, one of the } \\
\text { components is useless but adds to cost and adverse effect. }\end{array}$ \\
\hline Ceftriaxone+vancomycin & Antibiotic resistance which is a huge concern \\
\hline Azithromycin+cefixime & Antibiotic resistance and spectrum of activity differ \\
\hline
\end{tabular}

\section{DISCUSSION}

Older people take more medications as compared to the younger individuals because of the increased incidence of chronic problems.

Table 3 shows that in our study, the most commonly found disease was respiratory tract infections and percentage of antibiotics prescribed were above $90 \%$ which is very high compared to what the WHO standard (20.0-26.8\%) derived to be ideal and as compared to study finding. ${ }^{8}$

Drugs acting on gastrointestinal tract infections are the second most common (50\%) prescribed among them ranitidine was the most as previous study by Shah et al. ${ }^{9}$ Other drugs include vitamins and iron preparations along with analgesics and anti-inflammatory drugs (45\%) as conservative management of diseases for relief of pain and inflammation.

The study also revealed polypharmacy in geriatric patients with an average prescription of four drugs which also include analgesics and anti-inflammatory drugs along with antibiotics combinations which is higher. ${ }^{10,11}$

Few prescriptions (table: 4) had irrational drug combinations. This finding suggests that antibiotic prescribing needs to be regulated. The high percentage of antibiotics prescribed prescribers' belief that the therapeutic efficacy of single antibiotic is low. Tablet ranitidine was used along with antibiotic which is irrational unless patient complaints symptoms of gastritis.

Most of drugs were prescribed through oral route followed by injectables. Injectables form were used in serious condition.

According to Beers criteria, out of 200 patients few prescriptions were found as inappropriate which is due to weak evidence based guidelines in prescribing to elderly. ${ }^{12}$
A large number of prescriptions drugs were prescribed by brand names because of all medicines prescribed in the institution were free of cost to the patient. Interventions could target more appropriate drug selection by a physician to the elderly patients. ${ }^{13}$

\section{Limitations}

Relatively less number of patients was studied and prescriptions were not followed. The study was limited to in patient department of medicine, surgery, OBG and ENT. The study can be expanded in future including other departments to evaluate generalized pattern of drug utilization.

\section{CONCLUSION}

The study findings revealed an urgent need to address antibiotic prescribing practice in tertiary care hospital. Importantly few patients who received an antibiotic combination the prescription were irrational and polypharmacy is area of concern. In this regard development of antibiotic policy and making practice guidelines accessible to physicians while they are making clinical decisions. Increased used of generic alternative to brand product can be useful strategy in reducing cost and adverse drug reactions.

\section{Funding: No funding sources}

Conflict of interest: None declared

Ethical approval: The study was approved by the Institutional Ethics Committee

\section{REFERENCES}

1. Cho S, Lau SW, Tandon V, Kumi K, Pfuma E, Abernethy DR. Geriatric drug evaluation; where are we now and where should we be in future? Arch Intern Med. 2011;171:937.

2. Erwin WG. The Definition of Drug Utilization Review: Statement of Issues. Clin Pharmacol Therapeutics. 1991;50:596-9.

3. Veehof L, Stewart R, Haaijer-Ruskamp F, Jong BM. The development of polypharmacy:a longitudinal study. Fam Practice. 2000;17(3):261-7. 
4. Yegenoglu S, Baydar T. Information and observations of community pharmacists on geriatric patients: a qualitative study in Ankara city. Turk $\mathbf{J}$ Geriatrics. 2011;14(4):34-351.

5. Keshishian F, Colodny N, Boone RT. Physicianpatient and pharmacist -patient communication :geriatrics perceptions and opinions. Patient Education Counceling. 2008;71(2):265-84.

6. Sachdeva PD, Patel BG. Drug utilization studiesScope and future perspectives. Int J Pharmaceutical Biol Res. 2010;1(1):11-6.

7. Thomas M, Alexander B, Tony S, Andrei Z. Guidelines for implementing drug utilization review programs in hospitals. Russia: Management Sciences for Health; 1997.

8. Siguroardottir N, Nielsen AB, Munck A, Bjerrum L. Appropriateness of antibiotic prescribing for upper respiratory tract infections in general practice: Comparison between Denmark and Iceland. Scand J Prim Health Care. 2015;33(4):269-74.

9. Shah BR, Gajjar MB, Desai VS. Drug utilization pattern among geriatric patients assessed with the anatomical therapeutic chemical classification/ defined daily dose system in a rural tertiary care teaching hospital. Int J Nutr Pharmacol Neurol Dis. 2012;2(3):258-65.

10. Veehof LJG, Meyboom-De Jong B, HaaijerRuskamp FM. Polypharmacy in the elderly- a literature review. Eur J Gen Pract. 2000;6(3):98-106.

11. Teymoorian SS, Pal A, Hayley D. Risk factors for 30-day hospital readmissions in older adults. J Am Geriatr Soc. 2011;59:S188.

12. American Geriatrics Society 2012 Beers Criteria Update Expert Panel. American geriatrics Society updated Beers Criteria for potentially inappropriate medication use in older adults. J Am Geriatr Soc. 2012;60(4):616-31.

13. Taskeen M, Anitha N, Ali RS, Bharath R, Khan BA. A study on rational drug prescribing pattern in Hyderabad metropolitan. J Drug Deliv Ther. 2012;2(5):109-13.

Cite this article as: Tamma NK, Patnaik PK, Karedla S. Drug utilisation pattern in geriatric patients of a teritiary care teaching hospital: a retrospective study. Int J Basic Clin Pharmacol 2019;8:2450-3. 